\title{
FINAL QUALITY OF A SUSTAINABLE LANDFILL AND POST- CLOSURE MANAGEMENT
}

\section{Valentina Grossule}

DICEA, Department of Civil, Architectural and Environmental Engineering, University of Padova, via Marzolo 9, 35131 Padova, Italy
Article Info:
Received:
7 August 2020
Revised:
19 August 2020
Accepted:
24 August 2020
Available online:
27 August 2020
Keywords:
Closure of aftercare
Completion criteria
Final storage quality
Termination of aftercare

\begin{abstract}
Landfill should be designed and constructed in line with the principle of environmental sustainability, guaranteeing over a period of less than one generation (typically considered 30 years) the environmental equilibrium of Final Storage Quality, when waste stability and immobilisation of contaminants is achieved and all active measures of control may be removed without posing any further risk to the environment. The practical definition of FSQ, when a landfill can be released from aftercare, and a procedure for the technical and administrative termination of the post-closure management phase are an evident regulatory strategic need to assure the design of sustainable landfill. The aim of this paper is to provide a criterion to define the FSQ of landfill, based on the control of the analytical emission parameters and of stability indexes related to the residual emission potential. These should concur with the law's acceptance criteria for the landfilling of wastes (LAC), and with the legal limit values (LLV) established for the emission of contaminants into the environment. The interrelationship between, stability indexes (emission potential), analytical emission parameters, LAC and LLV is discussed and reference values are provided. Finally, the paper proposes a procedure for the termination of technical and administrative aspects following the post-closure management in accordance with FSQ.
\end{abstract}

\section{INTRODUCTION}

Despite the lack of a conventional definition for a sustainable landfill, in a scientific context a landfill is considered such if the emissions released do not modify substantially the quality of the surrounding environmental matrixes: air, water and ground (Hjelmar \& Hansen, 2005; Stegmann et al., 2003).

This concept is closely linked to Final Storage Quality (FSQ). The term "final storage" was first used during the mid-1980s by Baccini, Henseler and other researchers from the Swiss landfill working group (Belevi \& Baccini, 1989 ) in referring to the quality achieved by emissions and wastes at the time in which all active measures of control may be removed without posing any further risk to the environment. This condition of equilibrium should be reached within the time frame of one generation, commonly taken as a period of 30 years, in order to not "compromise the possibility for future generations to meet their needs" (WECD, 1987).

The European directive 1999/31/EC on waste landfilling established that to obtain a landfill permit from the authorities "adequate provisions, by way of a financial security or any other equivalent, on the basis of modalities to be decided by Member States, has been or will be made by the applicant prior to the commencement of disposal operation" (Article 8, point iv). The provisions laid down by the European directive have been implemented to varying degrees in national legislation (as an example, in Italy, landfill operators are required to provide financial provisions for at least 30 years following landfill closure). However, no criteria have been established relating to long-term emission control, with the exception of the placing of physical barriers, the efficacy of which, can be ensured merely for as long as the barriers themselves last. The contamination period of a landfill (intended as the time frame within which emissions may produce negative effects on the environment) however considerably exceeds the lifetime of physical barriers.

A stand-alone time-restricted financial provision would not appear to represent an adequate tool to ensure achievement of FSQ (Fourie, 2003). Moreover, the comprehensive attribution of responsibility to the operator with regard to the period in which the landfill may potentially elicit environmental issues is somewhat unrealistic as this period could be prolonged into centuries, extending beyond the timespan not only of the management company, but also of the relevant authorities (Gronow, 2014). Landfill design therefore should be addressed bearing in mind the role it
* Corresponding author

Valentina Grossule

email: valentina.grossule@unipd.it 
undertakes in a Circular Economy based on the following criteria:

a. A long-term perspective should be taken into account.

b. The limited duration of physical barriers should be addressed and measures taken to extend their lifespan for as long as possible.

c. Limits established by law relating to the emission of contaminants from liquid wastes (including sludges and digestates), from products deriving from recycling (compost, building materials) and the emission of gases into the environment should be taken into account.

d. The time frame required to achieve FSQ should be monitored and reduced to less than 30 years.

e. Legislation should be passed to include a Table of Minimum Objective values (TMO) to be reached prior to post-closure management of the landfill, establishing parameters and values based on scientific knowledge and reliable evidence.

f. Site-specific situations of environmental vulnerability should be considered, where necessary lowering the objective values or raising the degree of protection of individual barriers in the multi-barrier system.

g. All due caution should be exercised in the case of uncertainty when addressing all unsubstantiated aspects (wastes, technologies, etc.).

h. Mono-waste landfills should be preferred and classified based on the homogeneity of long-term behaviour of the specific wastes rather than on classification for inert, hazardous or non-hazardous wastes: e.g., landfills for municipal wastes, landfills for prevalently inorganic wastes, etc.

Accordingly, there is an evident strategic need for the definition of a reference framework for the Final Storage Quality of a landfill.

On the international scenario, the sole legislations to date to adopt a Table of Objective values relating to the achievement of Final Storage Quality by a sustainable landfill was issued by the Lombardy Regional Authorities, Italy (Guidelines for a sustainable landfill design and management, Regional Decree dated October 7th 2014, n. X, 246); while in Germany, several studies put forward FSQ values for use by the German Federal Environment Ministry (Stegmann, et al., 2006, Stegmann, et al., 2003, Stegmann, et al., 2011).

The aim of this paper is to provide a criterion to define the FSQ of landfill, based on the control of the analytical emission parameters and of stability indexes related to the residual emission potential. These should concur with the law's acceptance criteria for the landfilling of wastes (LAC), and with the legal limit values (LLV) established for the emission of contaminants into the environment (into surface waters, onto the soil, onto agricultural land as compost, domestic sludges, digestate, etc., or associated with building products realised with recycled residues). The interrelationship between, stability indexes (emission potential), analytical emission parameters, LAC and LLV is discussed and reference values are provided. Finally, the paper proposes a procedure for the termination of techni- cal and administrative aspects following the post-closure management in accordance with FSQ.

\section{CONTROL OF THE RESIDUAL EMISSION POTENTIAL OF WASTES AND FINAL STOR- AGE QUALITY OF THE LANDFILL}

Potential waste contaminants are essentially present in either a mobilizable $\left(s_{s}\right)$ or non-mobilizable form $\left(x_{s}\right)$. The mobilizable fractions contained in landfilled wastes are converted into a non mobile solid form or they are transformed and pass from one phase to another, in line with their characteristics of degradability and leachability, accumulating in the emissions generated (leachate and gas), and potentially polluting the environment. Thus, the mobilizable fraction represents the emission potential of landfill $\left(S_{t}\right)$.

The composition of both raw and pre-treated landfilled wastes varies over time, in particular the ratio between mobile and immobile contaminant fractions, reaching a peak in emission potential $\left(\mathrm{S}_{\max }\right)$ during the operation phase.

Figure 1 graphically illustrates the variation in emission potential of the wastes (associated with the residual mobile fraction of contaminants contained in landfilled wastes) based on the type of treatment undertaken (pre-treatment, in situ treatment carried out during landfill operations or post-closure). The graph is of purely indicative value.

The combination of pre-treatments and in situ treatments should be selected with the aim to achieve an environmentally sustainable value of residual emission potential $\left(\mathrm{S}_{\text {sust }}\right)$, - i.e. such to not disturb the environmental equilibrium (FSQ) - within the time frame of one generation, or however within the time frame covered by the financial provisions provided by the management company (30 years).

$\mathrm{RQ}$ represents Rock Quality, when waste is completely mineralized and the emission potential is negligible $\left(\mathrm{S}_{\mathrm{s}} \approx\right.$ $0)$. This condition is achieved over a variable time frame (diagenetic time frame).

To achieve FSQ, a series of quality objectives should be envisaged by the landfill design and management plan. These objectives should be established, in the same way as in numerous other areas of environmental protection, by defining a Table of Minimum Objectives (TMO).

When a landfill is sited on a vulnerable area (i.e. featuring a lower capacity of self-depuration), the local Authorities may pose more stringent values on the project in line with the degree of self-depuration of the environment (TPO - Table of Project Objectives). However, the TPO objectives may also come closer with TMO objectives when the designer includes an increased requirement of physical barriers (versus those established by law). Essentially, in a vulnerable area the landfill designer may intervene either on the quality of wastes (by lowering $S_{S}, S_{G}, S_{L}$ ) to achieve more restrictive project objectives (TPO) or on the quality of physical barriers to achieve project objectives resembling those established for TMO. The interrelationship between analytical emission parameters, stability indexes (emission potential), self-depuration capacity, addition of physical barriers (versus those provided for by law) and 


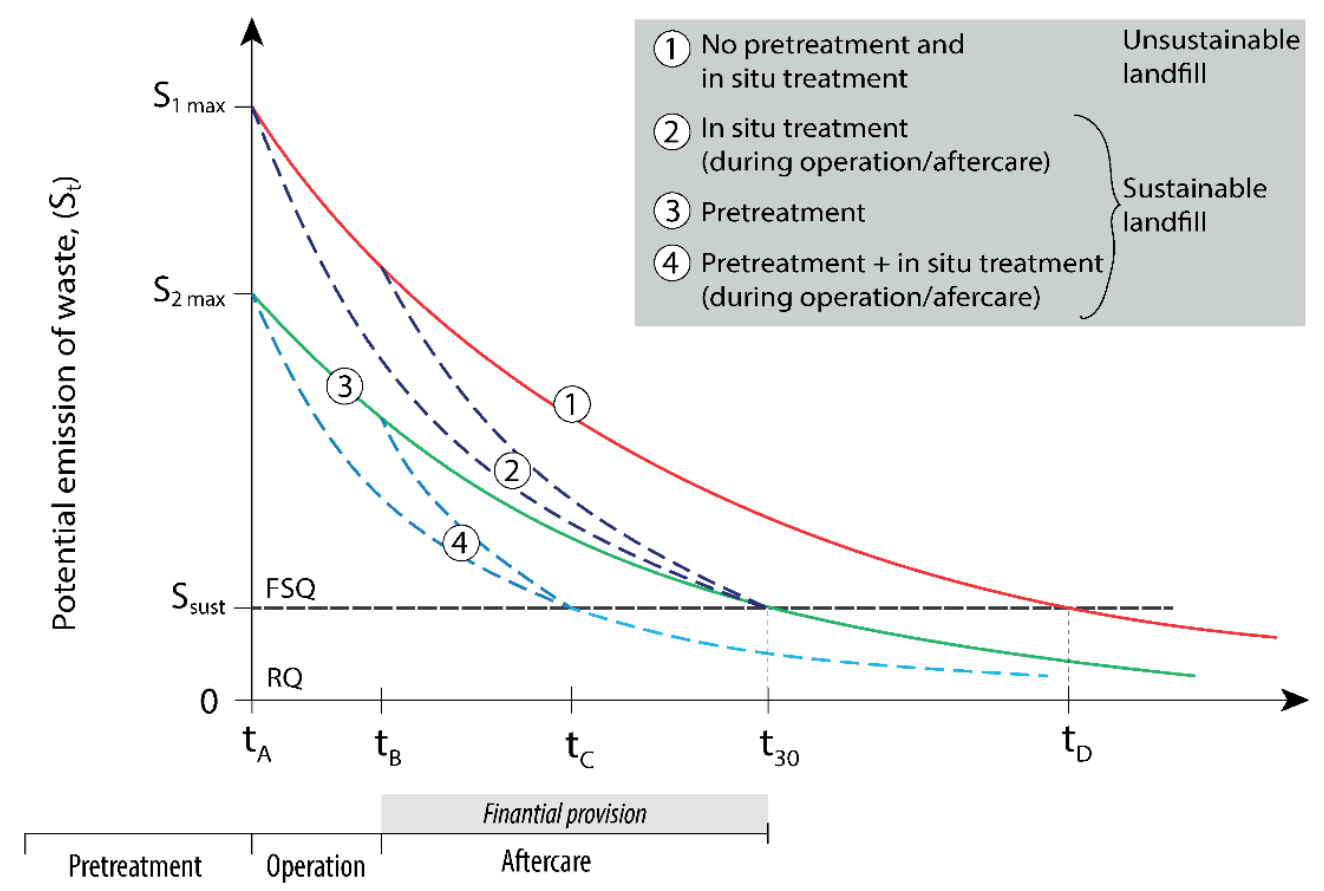

FIGURE 1: Time trend of the emission potential for release of contaminants from a landfill. FSQ= Final Storage Quality, according to which the emission potential reaches a value of $S_{\text {in }}$ in equilibrium with the environment; RQ, Rock Quality, according to which waste is completely mineralized and the emission potential $S_{S}=0$; $t_{A^{\prime}}$ peak in emission potential during landfill operations; $t_{B^{\prime}}$ Closure of landfill operations and commencement of aftercare; $t_{C^{\prime}}$ Anticipated achievement of FSQ; $t_{30}$, Sustainability target and termination of financial provisions; $t_{D^{\prime}}$ FSQ beyond the 30-year threshold (unsustainable landfill) (modified from Cossu et al., 2020c).

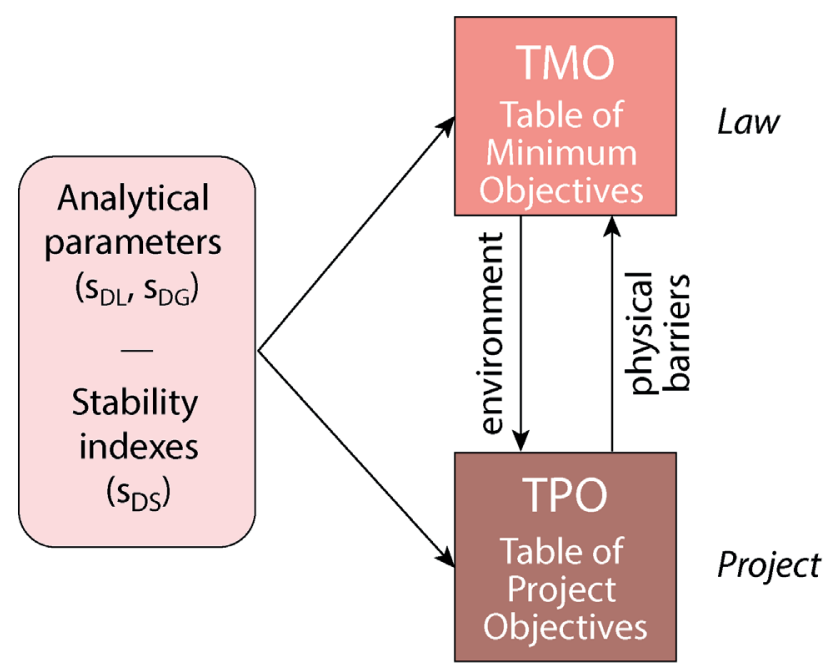

FIGURE 2: Relationship between parameters and stability indexes, self-depuration capacity of the environment and quality/efficiency of physical barriers used in addition to those established in the Table of Objective Project values (TPO), which may be more restrictive or equal to those provided for in the Table of Minimal Objective values established by law. $\mathrm{S}_{\mathrm{DS}}, \mathrm{S}_{\mathrm{DG}}, \mathrm{S}_{\mathrm{DL}}=$ residual concentration of contaminants present in wastes, gas and leachate, respectively.

TMO and TPO is reported in Figure 2.

The parameters considered in the Tables of Objectives (analytical parameters and stability indexes), to be discussed in detail in subsequent paragraphs, are identical to those used to assess waste acceptance criteria (AC Acceptance Criteria for the Landfilling of Wastes defined by Law), and should also be similar to those established by law for other sectors of environmental protection (Legal Limit Values- LLV). For example, they should concur with the parameters established for the emission of contaminants into surface waters and onto the soil, onto agricultural land (compost, domestic sludges, digestate, etc.) or associated with building products (realised with recycled residues).

Indeed, all operations implying the deposition of wastes on the land are liable to the release of emissions affecting the quality of the environment and therefore, in the same way as landfills, the potential impact produced over time and compliance with Final Quality should be considered, as an uncontrolled release of contaminants, even at low concentrations, could result in an increase of diffuse contamination.

A series of cases of deposition on the land are graphically represented in Figure 3 .

The interrelationship and scale of values for the diverse waste quality parameters are graphically illustrated in Figure 4, in which LAC represents the legally established quality parameters as acceptance criteria for the landfilling of wastes, PAC represents the waste acceptance values adopted by the designer, which may be either identical to or more restrictive than $\mathrm{LAC}$ values if more stringent pre-treatments than those established by law are applied, TMO and TPO refer to the previously described minimum and project objectives to be achieved in order to terminate the post-closure period of the landfill in line with FSQ, and LLV the legal limit values established for the emission of contaminants into the environment referred to previously.

Essentially, a similar strategy to that applied in the treat- 

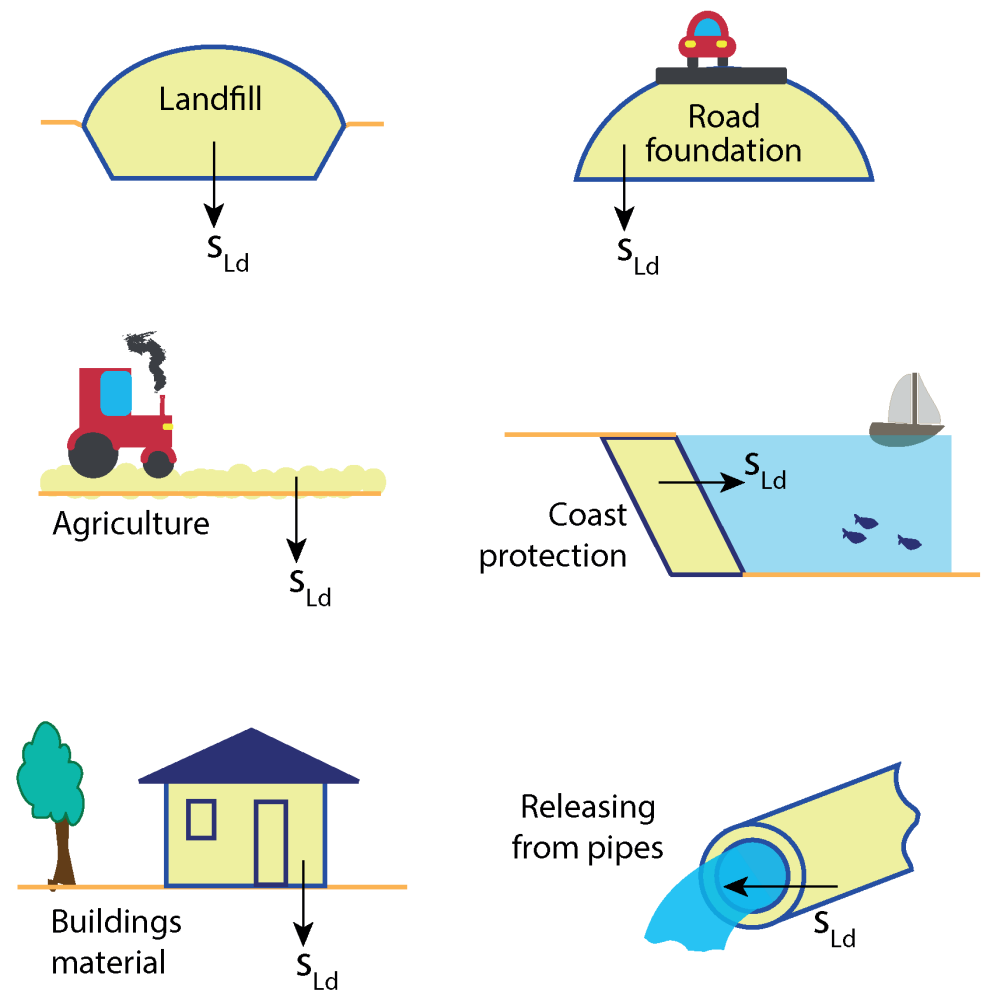

FIGURE 3: Graphical representation of the potential release of contaminants from different forms of waste depositing on the land (Modified from Scharff, 2014; Cossu et al., 2020). $s_{\mathrm{Ld}^{\prime}}$ concentration of mobile contaminants dispersed through leaching.

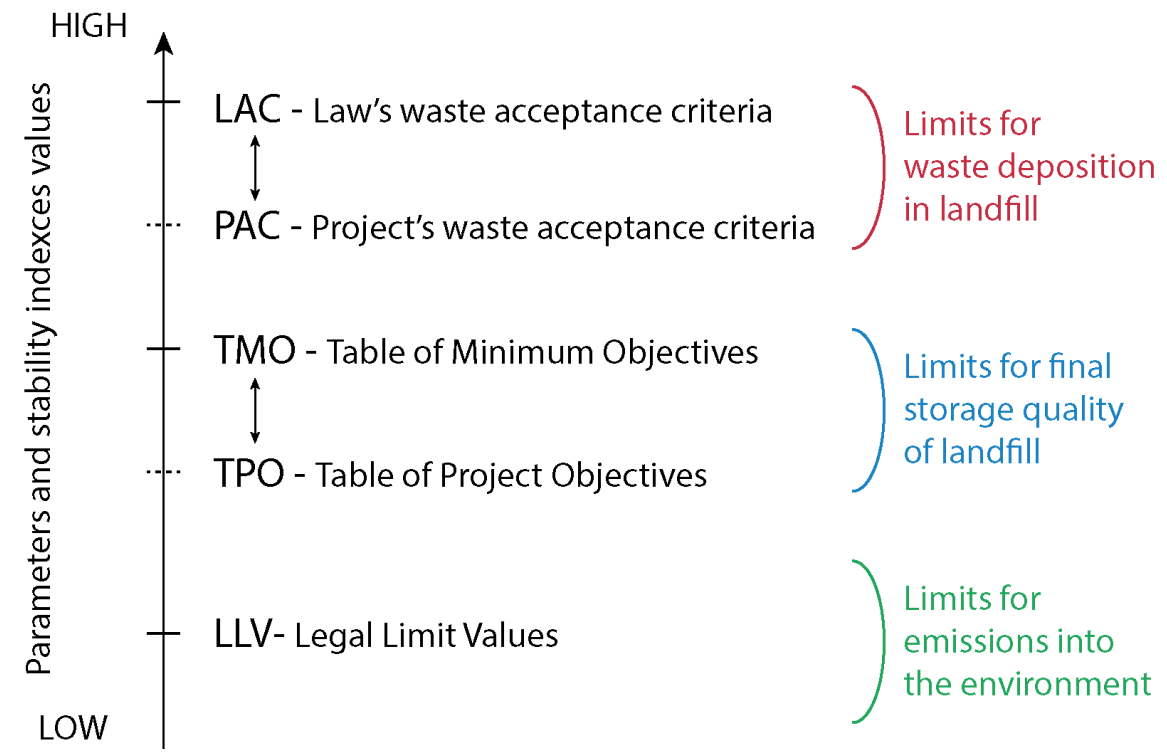

FIGURE 4: Interrelationship and scale of values for parameters and stability indexes that contribute towards defining a series of waste quality objectives.

ment of wastewaters, for example, should be adopted (Figure 5).

Should the need arise to dispose of industrial wastewaters containing $1500 \mathrm{mg} / \mathrm{L}$ Total Nitrogen (TN) in a wastewater treatment plant, industry would be required to pre-treat the wastewater to comply with acceptance limits for sewerage systems (LAC, Legislative Decree 152, 2006).
While the depuration plant would be dimensioned in order to meet the discharge legal requirements (TMO). However, should the area in which the treated effluent is released be a vulnerable area (water body featuring a poor exchange subject to eutrophication), i.e. the Venetian lagoon, lower concentrations should be present on release, and the plant should be designed, built and managed with the aim of achieving this objective (TPO). 


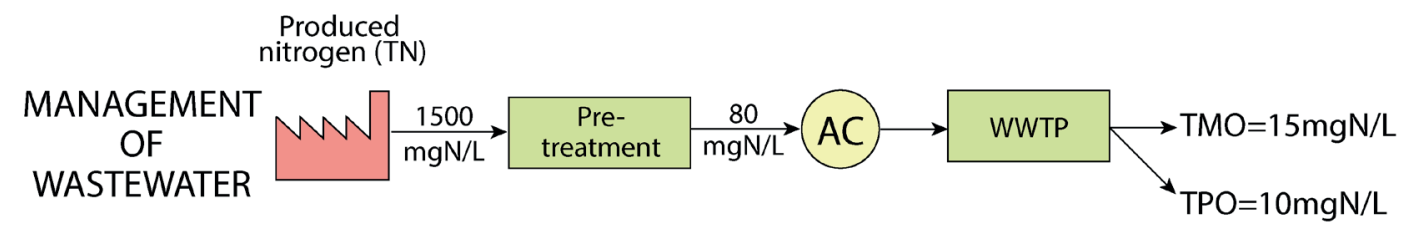

Environment

environment
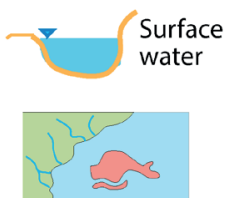

Dlscharge in Venice Lagoon*

\section{MANAGEMENT OF WASTE TO LANDFIL}

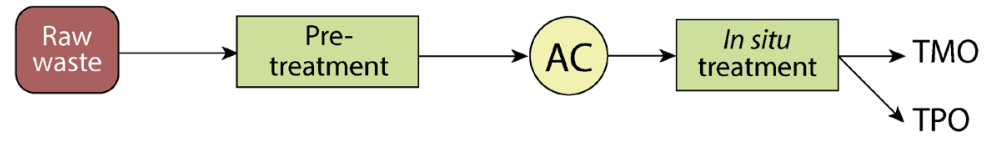

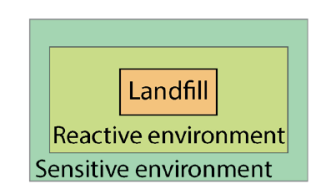

FIGURE 5: Graph parallel between the management of sewage forwarded to a depuration plant and management of wastes forwarded to landfill. WWTP, Wastewater treatment plant. *Limits for discharge into the Venice lagoon laid down in Ministerial Decree 30/7/99.

\section{EMISSION PARAMETERS}

Gas and leachate emissions that form inside a landfill are the result of complex biochemical, geochemical and chemical-physical reactions and interactions between the three phases co-existing heterogeneously in the waste mass of a landfill. The emissions quality may be characterised by a series of different analytical and operational parameters taken to describe Landfill Quality and changes over time (Heyer and Stegmann, 2018; Cossu and Pivato, 2018).

\subsection{Biogas}

Parameters used to characterise biogas are:

- Percentage composition (\%): $\mathrm{CH}_{4} \%, \mathrm{CO}_{2} \%, \mathrm{O}_{2} \%$.

- Hourly production of biogas $\left(\mathrm{Nm}^{3} / \mathrm{h}\right)$ : this may be measured by means of extraction tests in the presence of a gas collection system, or using a standardised model of biogas production (Andreottola et al., 2018);

- Specific production of biogas $\left(1 / \mathrm{m}^{2} \mathrm{~h}\right)$ : this parameter may be used to estimate surface emission of biogas and the eventual oxidative capacity of the top cover; measurements may be taken from static or dynamic surface accumulation chambers and subsequent instrumental analysis of the accumulated gas.

Amongst the above parameters, the percentage composition of biogas may not be significant in assessing the degree of stability reached by wastes due to the fact that the concentration of putrescible organic substances affects the quantity of gas generated but has a negligible influence on quality. The latter is linked solely to the degradation stage reached and potential infiltration of air. With regard to safety, the accumulation of low gas loads may determine the same risks as higher gas loads (fire, explosions, plant asphyxiation).

It might also be of interest to assess the $\left(\mathrm{CH}_{4}+\mathrm{CO}_{2}\right)$ / $\mathrm{N}_{2}$ ratio: indeed, the latter yields useful information for the characterisation of biogas quality in both aerobic and anaerobic environments. The ratio is associated with nitrogen which, contrary to oxygen, is not consumed during degradation reactions. This parameter may prove to be of use in assessing the degree of stability reached by wastes and verifying air ingress into the landfill body.

\subsection{Leachate}

To assess leachate quality, the following parameters are commonly analysed:

- Chemical Oxygen Demand, $\operatorname{COD}\left(\mathrm{mgO}_{2} / \mathrm{L}\right)$;

- Biochemical Oxygen Demand over 5 days, $\mathrm{BOD}_{5}$ $\left(\mathrm{mgO}_{2} / \mathrm{L}\right)$;

- Total Organic Carbon, TOC (mg/L). (As this parameter can be analysed both on liquid and solid matrix, it is normally used for carbon mass balance);

- Dissolved Organic Carbon, DOC (mg/L): the fraction of TOC dissolved in water defined as the fraction capable of passing through a 0.7-0.22 filter. As discussed in detail subsequently, DOC has been adopted by the EU as one of the most important parameters to be considered when establishing waste acceptance criteria for landfilling;

- Heavy metals (mg/L);

- Other substances, such as chlorides, sulphates, and fluorides are also taken into account when assessing acceptability;

- Total Kjeldahl Nitrogen, TKN (mgN/L);

- Ammonium Nitrogen, $\mathrm{N}-\mathrm{NH}_{4}{ }^{+}(\mathrm{mgN} / \mathrm{L})$ : under anaerobic conditions ammonium cannot be oxidised;

- Nitric and nitrous nitrogen, $\mathrm{N}-\mathrm{NO}_{2}, \mathrm{~N}-\mathrm{NO}_{3}^{-}(\mathrm{mgN} / \mathrm{L})$ : the oxidised forms of nitrogen are usually only present in leachate from aerobic or semi-aerobic landfills.

In addition to concentrations of the above-mentioned substances, the ratios between the diverse parameters are highly significant, both in terms of assessment of FSQ and in ascertaining environmental situations featuring the presence of contaminants with different origin. For example:

$\mathrm{BOD}_{5} / \mathrm{COD}$ yields information relating to the residual biodegradability of leachate and an eventual contamination of surface waters or water tables. Generally, as biological stabilisation progresses in the landfill, a rapid decrease in in this ratio is observed due to a rapid uptake of $\mathrm{BOD}_{5}$, whilst $\mathrm{COD}$ rarely reaches values lower than $500-1000 \mathrm{mgO}_{2} / \mathrm{L}$ due to the presence of non-degradable humic substances.

- $\mathrm{NH}_{4} / \mathrm{TKN}$ provides an indication of the state of hydrolysis of organic nitrogen and ammonium. 
- $\mathrm{NH}_{4} / \mathrm{Cl}^{-}$. As these substances are both conservative in an anaerobic environment, this ratio allows the origin of ammonium to be determined in the presence of two sources of emission (e.g. leachate from an MSW landfill and runoff from agricultural land fertilised with urea).

- Nitrites and nitrates/TKN. The ratio between the oxidised form of nitrogen and Kjeldahl nitrogen attests to the type of biological processes (aerobic or anaerobic) present within the waste mass.

\section{PARAMETERS FOR USE IN MEASURING SOLID WASTE QUALITY AND ASSESSING EMISSION POTENTIAL}

Waste quality may be defined based on the following parameters:

- Concentration (expressed as \% or $\mathrm{mg} / \mathrm{kg}$ ). This is usually employed to measure the overall quantity of a given substance present in waste either in a mobile $\left(\mathrm{s}_{\mathrm{s}}\right)$ or non mobile form $\left(\mathrm{x}_{\mathrm{s}}\right)$, using analytical techniques that vary in line with the substance to be measured.

- Emission potential. This assesses, both directly and indirectly, the amount of contaminant (mobilizable fraction) present in a waste. It may be measured by means of tests providing a standardized, controlled reproduction of the processes which mobilise the contaminant. Tests most frequently applied in the case of wastes destined for landfilling are aimed at assessing the biological degradation of organic substances and leaching.

Cyclical tests facilitate the monitoring over time of the evolution of emission potential based on decay curves such as those represented in Figure 1.

The aim to minimise emission potential and promote long-term stabilisation should therefore be defined on the basis of proven scientific knowledge where possible, or by means of experimental trials when dealing with specific wastes and contaminants for which appropriate information is lacking. A similar procedure is adhered to in the treatment of wastewaters. The performance of biological depuration process applied to domestic wastewaters are widely acknowledged and standardized, whilst wastewaters of a different origin may require a pilot study to be carried out in order to define the necessary design parameters.

\subsection{Tests applied in measuring the degree of bio- degradation}

These tests may be conducted by measuring parameters indicative of biodegradation trend, i.e.:

\section{$\mathrm{O}_{2}$, consumed under aerobic conditions;}

Gas, produced under anaerobic conditions;

$\mathrm{CO}_{2}$, produced under aerobic or anaerobic conditions;

- Ratio between parameters in eluate from leaching tests.

Tests may therefore be used to assess both the presence of biodegradable substances in the wastes (indirectly) and thier biological stability.
The most commonly used indexes are respirometric and gas production indexes.

The respirometric index measures oxygen consumed by a unit of weight of waste or biomass (expressed as Total Solids -TS or Volatile Solids -VS) over a specific time frame. The test may be carried out under static or dynamic conditions (Cossu et al., 2001; Cossu \& Raga, 2008). Static respirometric indexes $\left(\mathrm{RI}_{4}, \mathrm{RI}_{7}\right)$ measure oxygen consumed over a 4- or 7-day period and are usually expressed in terms of $\mathrm{mg} \mathrm{O}_{2} / \mathrm{g}$ solids (TS or VS). Dynamic respirometric indexes (DRI) measure the oxygen consumed hourly by a stabilised air flow that crosses the wastes, expressed as $\mathrm{mgO}_{2} / \mathrm{kgVS} / \mathrm{h}$.

$\mathrm{GB}_{21}$, used to measure gas production over a 21-day period, is widely used in the presence of biogas. It may be expressed in terms of NL (gas volume under normal conditions, $0^{\circ} \mathrm{C}, 1 \mathrm{~atm}$ ) per $\mathrm{kg}$ of TS or VS.

The above-mentioned indexes, although very popular, feature a series of drawbacks:

- High cost of equipment (both static and dynamic);

- Low significance of results in the presence of toxic or inhibitory substances (that slow down oxygen consumption) or inert volatile solids (such as paper or plastic) which, being at the denominator, tend to underestimate the index (Cossu et al., 2012).

To overcome these drawbacks (Cossu et al., 2012; Cossu et al., 2017), use of the $\mathrm{BOD}_{5} / \mathrm{COD}$ ratio measured on the eluate of a simple leaching test has been proposed (several leaching test conditions have been tested, varying testing mode -static or dynamic-, contact time, liquid to solid ratio and pretreatment).

Figure 6 illustrates the correlation between several diverse indexes as resulting from a series of experimental studies.

The index yields two types of information: the presence of organic substances (COD) and degree of biological stabilisation $\left(\mathrm{BOD}_{5} / \mathrm{COD}\right)$. Should a finding of null $\mathrm{BOD}_{5}$ be detected in the presence of a high COD, this would indicate the need to assess the presence of toxic or inhibitory compounds. This index is also advantageous in that measurements are not affected by the presence of paper and plastic and is suitable for use in measuring both fine and coarse material.

Biological stability indexes are indicated for use at different times throughout the life of a landfill for a series of reasons: following mechanical-biological pre-treatment to verify process efficiency prior to waste deposition, to check compliance with waste acceptance criteria, and on termination of the post-management phase to verify achievement of FSQ. The parameters and units of measure used may vary in line with the purposes for which they are applied. As an example, the $\mathrm{BOD}_{5} / \mathrm{COD}$ ratio is highly effective in assessing degree of waste stabilisation following pre-treatment or on termination of the post-management phase, whilst $\mathrm{RI}_{4}$, measured in $\mathrm{mgO}_{2} / \mathrm{gTS}$, provides a reliable indication of the putrescible content of wastes accepted for landfilling. However, $\mathrm{BOD}_{5} / \mathrm{COD}$ should be measured even when using $\mathrm{RI}_{4}$ to assess the potential presence of inhibitory factors. 
a

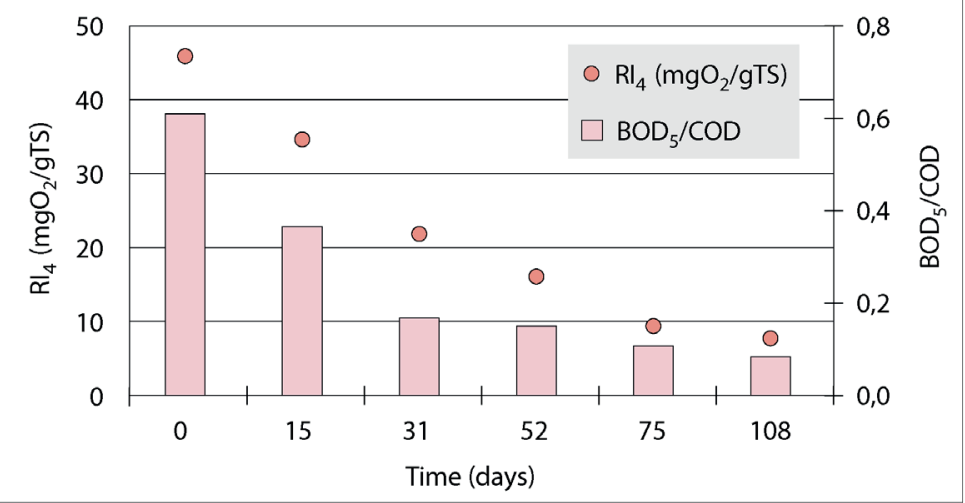

b

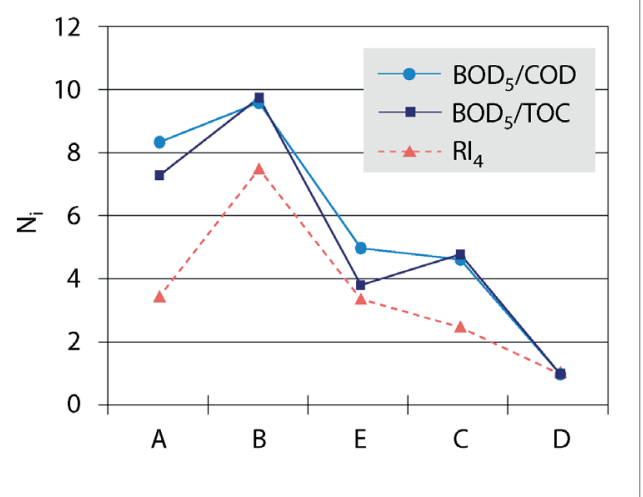

FIGURE 6: Correlation between respirometric index RI4 and BOD5/COD ratio. a. Variation of the two indexes in a lysimeter-conducted stabilisation process of pre-treated municipal wastes (modified from Cossu \& Raga, 2014). b. Correlation between normalised values of different biodegradation indexes for various types of waste: $A$ \& B = mechanically pre-treated undifferentiated wastes; $C$ = wastes following Mechanical-Biological Treatment; $\mathrm{D}=$ compost from anaerobic digestate; $\mathrm{E}=$ dried domestic sludge. Ni= Normalised values based on waste stability index for wastes $\mathrm{D}$, taking $\mathrm{D}$ as unitary $\mathrm{D}, \mathrm{Ni}=$ Stability index measured for waste i / Stability index measured for waste $\mathrm{D}$. BOD/COD and BOD/TOC indexes were measured following static leaching test having a time of contact between liquid and solids of $2 \mathrm{~h}$, without shaking; (modified from Cossu et al., 2017).

Although this issue is widely debated throughout the scientific community worldwide, very few countries have included in national legislation indexes for use in assessing the stability of landfilled wastes, as illustrated in Table 1 that provides updated information on this topic.

The European Union has established a limit value for COD, whilst leaving it up to each single nation to deliberate on additional criteria and limits.

German and Austria adopt a 4-day static index (indicated as $A T_{4}$ ), the United Kingdom applies the 4-day dynamic respirometric index $\left(\mathrm{DRI}_{4}\right)$ and potential production of methane at 100 days $\left(\mathrm{BMP}_{100}\right)$, whilst in Italy, the Italian National Institute for Environmental Research and Protection (ISPRA) has adopted the dynamic index.

Generally speaking, the other European countries tend to adopt the COD limit, although at times exceptions are made for municipal wastes.

In several countries such as China and Spain, where no additional checks are carried out, working groups have been set up with the aim of defining possible criteria for future use, although currently limits have only been established by a restricted number of local authorities.

TABLE 1: Verification of the biological stability of wastes prior to landfilling and criteria per assessment applied in different countries.

\begin{tabular}{|c|c|c|c|c|}
\hline Country & Verification & Index & Limit value & Reference \\
\hline Australia & NO & - & - & (Clarke, 2020) \\
\hline Austria & YES & $\mathrm{RI}_{4}, \mathrm{~GB}_{21}$ & $(7 \mathrm{mg} \mathrm{O} / \mathrm{g} \mathrm{TS} 20 \mathrm{Nl} / \mathrm{kg} \mathrm{TS})^{\text {a }}$ & (Binner, 2020) \\
\hline China & NO & $\mathrm{RI}_{4}^{\mathrm{b}}$ & $20 \mathrm{mg} \mathrm{O} / \mathrm{g}$ TS & $(\mathrm{He}, 2020)$ \\
\hline Colombia & NO & - & - & (Gandini, 2020) \\
\hline EU & YES & COD & $80 \mathrm{mg} / \mathrm{L}$ & (EU- Landfill Directive 31/99) \\
\hline France & $\mathrm{NO}^{\mathrm{c}}$ & - & - & (Hennebert, 2020) \\
\hline Germany & YES & $\mathrm{RI}_{4}, \mathrm{~GB}_{21}$ & $5 \mathrm{mg} \mathrm{O} / \mathrm{g} \mathrm{TS}, 20 \mathrm{Nl} / \mathrm{kg}$ TS & (Ritzkowski, 2020) \\
\hline Japan & NO & - & - & (Ishii, 2020) \\
\hline Greece & $\mathrm{NO}^{\circ}$ & - & - & (Komilis, 2020) \\
\hline Italy & YES & DRI & $1000 \mathrm{~g} \mathrm{O}_{2} / \mathrm{kg} \mathrm{VS}^{\star h}$ & (DM 27 set. 2010) \\
\hline Holland & $\mathrm{NO}^{\mathrm{c}}$ & - & - & (van der Sloot, 2020) \\
\hline UK & NO & $\mathrm{DRI}_{4}, \mathrm{BMP}_{100}$ & - & (Knox, 2020) \\
\hline Spain & $\mathrm{NO}^{\mathrm{c}}$ & - & - & (Sanchez, 2020) \\
\hline Sweden & $\mathrm{NO}^{\mathrm{c}}$ & - & - & (Kumpiene, 2020) \\
\hline USA & NO & - & - & (Thorneloe, 2020) \\
\hline
\end{tabular}

a. Both limits must be complied with

b. Adopted only on a local level in Shanghai

c. No supplementary indexes used in addition to those indicated by the European directives 


\subsection{Leaching tests}

Leaching tests have been extensively studied and standardized for use in a series of diverse applications both in Europe and the US (van der Sloot et al., 2018). In particular, the European Union has widely endorsed use of these tests in defining waste acceptance criteria for landfilling.

To ensure the appropriateness of leaching tests to act as a technical reference, they should be standardized and officially recognised.

The following variables should be considered with regard to standardization:

- Liquid/solid ratio (L/S);

- Type of contact between liquid and solids (static or dynamic, batch or in leaching columns);

- $\mathrm{pH}$ (fixed or variable);

- Quality of leached liquid;

- Duration of contact between liquid and solids;

- Physical conditions of the solids (granular, monolithic);

- Other control parameters (redox potential, complexation capacity, etc.).

Aims of the test: to assess release over time or variation in control parameters (Figure 7).

Whilst taking the above into account, a plethora of standards exist to be used for a wide variety of purposes, thus resulting in the European Committee for Standardization issuing waste characterisation guidelines (CEN TC292) to facilitate navigation amongst the diverse standards (EN 12920), (van der Sloot et al., 2014).

Without wishing to comment on which test performs best in identifying a Leaching Index to be used in defining a Table of Objectives (TMO) to enhance achievement of FSQ, it should be highlighted how this problem is identical to that presented in the context of landfilling of any other product and/or residue (see Figure 3 ) or in defining the End of Waste for construction and demolition wastes. Therefore, if a standard is established for these situations, a similar standard should be defined also for FSQ.

A

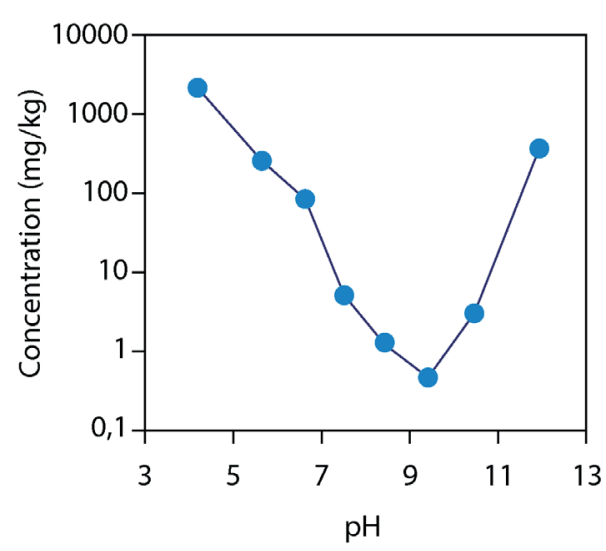

5. CRITERIA FOR THE DEFINITION OF OBJECTIVE VALUES RELATING TO FINAL STORAGE QUALITY

The criteria used to define a Table of Minimum Objectives to act as a reference guideline in landfill design should include the following:

- Analogy with parameters of waste characterisation for the purpose of identifying acceptance criteria for landfilling.

- Analogy with parameters and values defined for "End of Waste" products used on soil, i.e. recycled material in road foundation, use of digestate in agriculture, etc.

- Analogy with parameters and limits established for the discharge of wastewaters into water bodies and of gas effluents into the atmosphere.

- Acknowledgement that an increasing level of pollution constitutes one of the major macro-environmental issues and asking questions such as: "Is it preferable to have industrial wastes recycled in bitumen of numerous roads or to deposit them in a sustainable landfill?"

- "End of waste qualification" and "Termination of the post-management phase of a landfill" are two faces of the same coin.

- Limits of concentration for leachate contaminants to be established for TMO should take into account the limited duration of physical barriers.

For the sake of rapid comparison, Table 2 lists the quality objectives established with a view to monitoring environmental impact for use in the measurement of different parameters on a range of liquid (leachate, eluates from leaching tests, wastewaters) and solid matrixes. Intentionally, no Minimum Objective Values (TMO) are proposed for the design of a sustainable landfill as this should be subjected to an institutional assessment conducted ad hoc by a working group set up for this purpose. As a mere example, the TMOs adopted in the Sustainable Landfill Guidelines issued by the Lombardy Regional Authorities in 2014 and the objective values suggested by Stegmann et al. (2006) are reported.

B

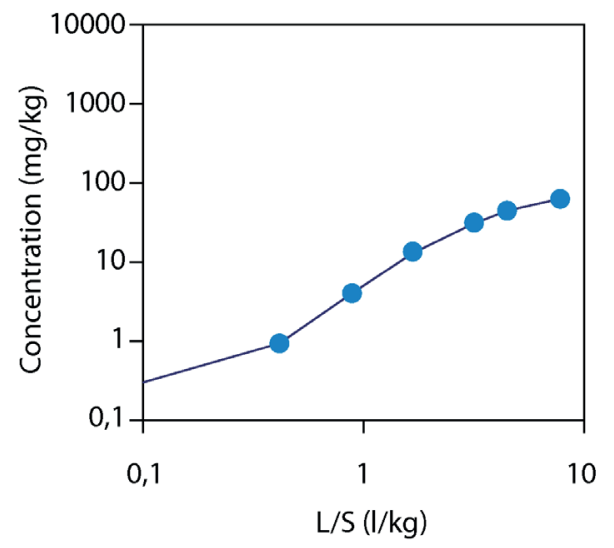

FIGURE 7: Variation of contaminant release in leaching tests according to changes in control parameters (A) or time span (measured in terms of L/S) (B) (modified from van der Sloot et al., 2014).. 


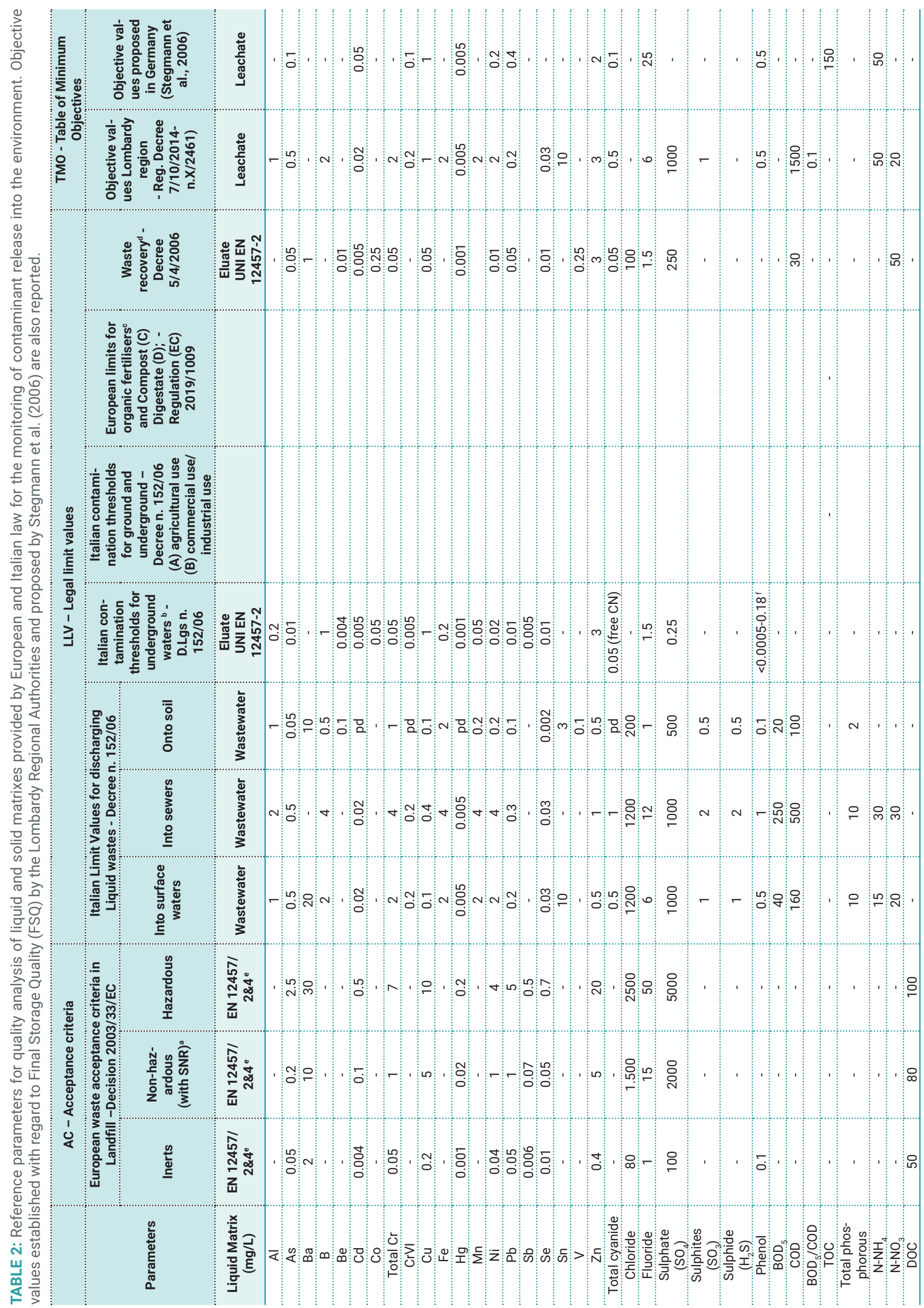




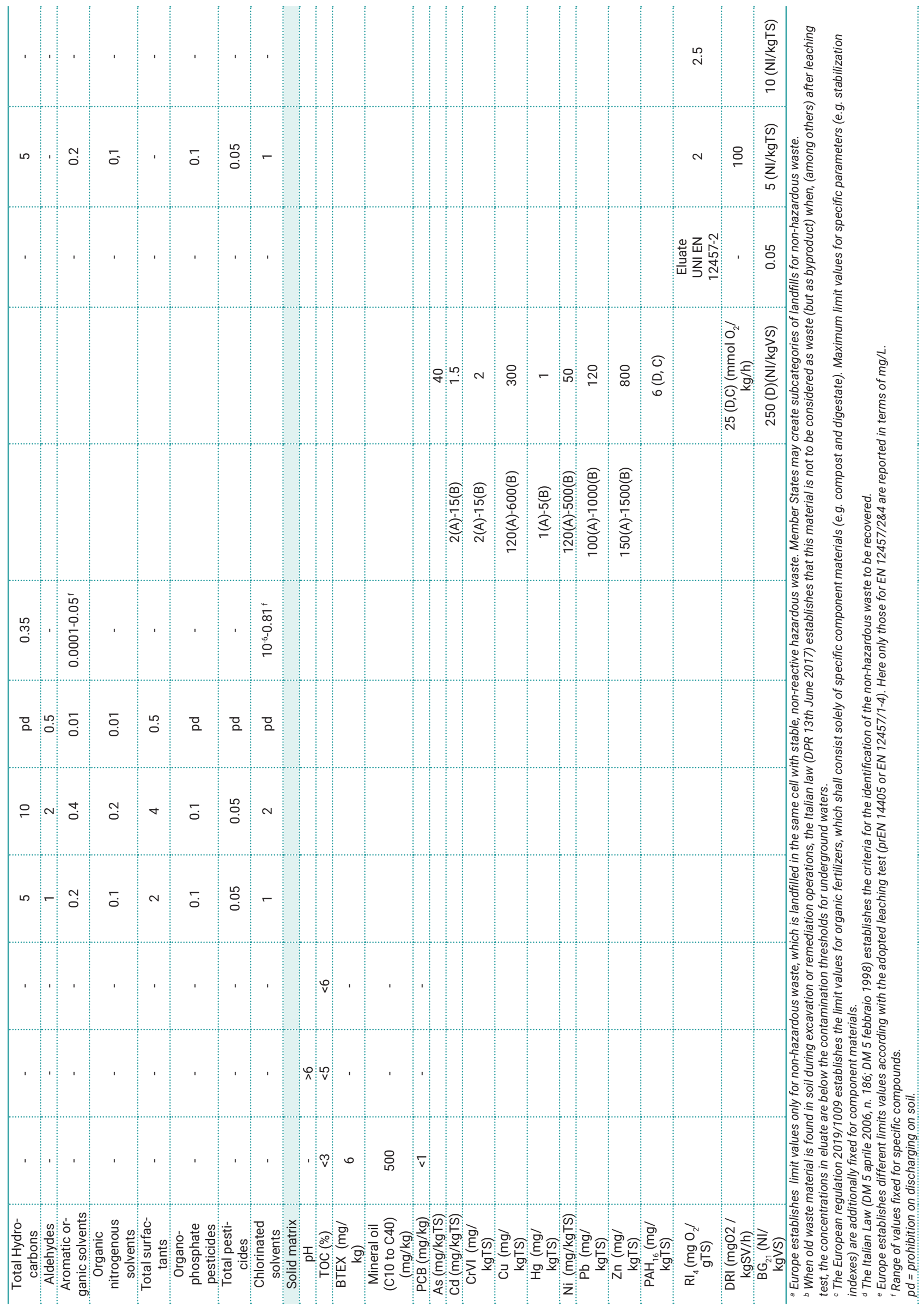




\section{PROCEDURES FOR TERMINATION OF POST-CLOSURE MANAGEMENT}

The procedure proposed for the termination of technical and administrative aspects following the post-closure management is based on verification of the achievement of the project objectives established in the TPO.

During the post-closure management phase in a landfill, the operators should monitor quality evolution over time. Once conditions meeting the TPO objectives have been satisfactorily reached, the operator should liaise with the relevant Authorities to obtain authorisation to undertake the termination procedure (Figure 8). A gas, waste and leachate sampling schedule is established for a series of collection point at varying depths, and all tests and analyses envisaged by the project are carried out.

If the results obtained meet the limits established by the TPO, the procedure is then repeated for a specific number of times (for example, 3 times) at a pre-established time interval (e.g. 1 month). If values are confirmed, the Administrative authorities may authorise termination of the post-closure phase.

However, if values are not confirmed and the discrepancies are only slight, the Authorities may opt to undertake a risk analysis to assess whether residual values, although exceeding those targeted by the TPO, are compatible with the environmental situation with regard to the quality of emissions and level of residual protection afforded by physical barriers.

Should the risk analysis yield a positive outcome, the post-closure period may be terminated. Conversely, the post-closure management phase should continue, awaiting the onset of suitable conditions to repeat the procedure.

\section{DECOMMISSIONING}

Once the landfill has achieved final storage quality, compliance with the project objectives has been achieved and post-closure management has officially been terminated, the landfill is then ready for Decommissioning. Decommissioning represents the definitive release of the landfill to nature and to its intended end use in the absence of any further human interventions other than those required to promote end use, in line with the definition of FSQ provided by Baccini \& Belevi (1989).

Accordingly, no further monitoring should be required with regard to control of emissions, leachate pumping, maintenance of cover systems or leachate drainage.

To enable the above, the topic should be addressed right from the design stage, as an example, by providing for morphologies that envisage build-up of the waste mass above ground level (see Chapter 3, paragraph 3.15), thus facilitating by reasons of gravity, water runoff from the inside of the landfill. Morphologies that develop the waste mass below ground level, although less critical with regard to mechanical stability, may act as a water storage basin, thus determining a potential uncontrolled outflow of liquid. In this case, appropriate systems of controlled water overflow and drainage of emissions should be implemented.

\section{CONCLUSIONS}

The practical definition of FSQ, when a landfill can be released from aftercare, and a procedure for the technical and administrative termination of the post-closure management phase are an evident regulatory strategic need to assure the design of sustainable landfill. To achieve FSQ, a series of quality objectives should be envisaged by the landfill design and management plan. These objectives should be established by defining a Table of Minimum Objectives (TMO), which should be used as reference in establishing the Table of Project Objectives (TPO). The procedure for the closure of the aftercare should be based on verification of the achievement of the project objectives. The establishing of TMO and TPO, as well as the aftercare closure procedure should be in line the following criteria:

Minimum Objectives fixed by the TMO may coincide with the Project Objectives (TPO), but in case landfill is sited on a vulnerable area, authorities may pose more stringent values on the project, in line with the degree of self-depuration of the environment and with the further physical barriers (versus those established by law) that the designer might include in the project.

TMO and TPO parameters should be analogous with parameters fixed for waste acceptance for landfilling, for "End of Waste" products used on soil, (i.e. recycled material in road foundation, use of digestate in agriculture, etc.) and for the discharge of liquid and gaseous emission into the environment.

Once compliance with the project objectives has been achieved, post-closure management can be terminated. In case limit values are not achived, risk analysis might be carried out to assess whether residual values, although exceeding those envisaged by the TPO, are compatible with the environmental situation with regard to the quality and level of residual protection afforded by physical barriers.

\section{REFERENCES}

Andreottola, G., Cossu, R., Ritzkowski, M., 2018. Landfill gas generation modeling. In: Cossu, R., Stegmann, R., 2018. Solid waste landfilling: Concepts, processes, technologies. Chapter 9.1, 419-438. Elsevier Publisher, ISBN: 978-0128183366.

Belevi H., Baccini P. (1989). Long-term behaviour of municipal solid waste landfills. Waste Management and Research 7 (1989) 43-56.

Binner E., 2020. BOKU University, Wien. In: Cossu, R., Grossule, V., Lavagnolo, M.C., 2020. La discarica sostenibile: Ruolo nell'Economia Circolare e proposte normative. CISA publisher, ISBN: 97888626 50182

Clarke W. , 2020. University of Queensland, Australia. In: Cossu, R., Grossule, V., Lavagnolo, M.C., 2020. La discarica sostenibile: Ruolo nell'Economia Circolare e proposte normative. CISA publisher, ISBN: 9788862650182.

Cossu R., Fantinato G, Pivato A., Sandon A., 2017. Further steps in the standardization of BOD5/COD ratio as a biological stability index for MSW. Waste Management 68 (2017) 16-23

Cossu, R., Lai, T., Sandon, A., 2012. Standardization of BOD5/COD ratio as a biological stability index for MSW. Waste Manage. 32, 1503-1508.

Cossu, R., Laraia, R., Adani, F., Raga, R., 2001. Test methods for the characterization of biological stability of pre-treated municipal solid waste in compliance with EU directives. In: Proceedings Sardinia 2001, Eighth International Waste Management and Landfill Symposium, 1-5 October 2001. Cagliari, Italy. 
Cossu, R., Pivato, A., 2018. Aftercare completion: Final storage quality assessment. In: Cossu, R., Stegmann, R., 2018. Solid waste landfilling: Concepts, processes, technologies. Chapter 16.1, 887-898. Elsevier Publisher, ISBN: 978-0128183366.

Cossu, R., Raga, R., 2008. Test methods for assessing the biological stability of biodegradable waste. Waste Manage. 28, 381-388.

Cossu, R., Raga, R., 2014. Test methods for assessing the biological stability of biodegradable waste. In: Cossu R., van der Sloot H., 2014. Sustainable landfilling. Cap. 13, 658-672. CISA Publisher, ISBN: 978-88-6265-005-2.

Fourie A.B., Morris J.W.F. (2003). The irrelevance of time as a criterion for aftercare provision. Proceedings Sardinia 2003. Ninth International Waste Management and Landfill Symposium.

Gandini M., 2020. Universidad Autónoma de Occidente, Cali, Columbia. In: Cossu, R., Grossule, V., Lavagnolo, M.C., 2020. La discarica sostenibile: Ruolo nell'Economia Circolare e proposte normative. CISA publisher, ISBN: 9788862650182.

Gronow, J., 2014. Landfilling - The road less travelled. In: Cossu R. van der Sloot H., 2014. Sustainable landfilling. Cap. 2, 63-74. CISA Publisher, ISBN: 978-88-6265-005-2.

He, P., 2020. Tonji University, Shanghai. In: Cossu, R., Grossule, V., Lavagnolo, M.C., 2020. La discarica sostenibile: Ruolo nell'Economia Circolare e proposte normative. CISA publisher, ISBN: 97888626 50182.

Hennebert P., 2020. Institut national de l'environnement industriel et des risques (INERIS), France. In: Cossu, R., Grossule, V., Lavagnolo, M.C., 2020. La discarica sostenibile: Ruolo nell'Economia Circolare e proposte normative. CISA publisher, ISBN: 9788862650182.

Heyer K.U., Stegmann, R., 2018. Leachate quality. In: Cossu, R., Stegmann, R., 2018. Solid waste landfilling: Concepts, processes, technologies. Chapter 10.2, 511-540. Elsevier Publisher, ISBN: 9780128183366

Hjelmar O., Hansen J.B., 2005. Sustainable landfill: the role of Final Storage Quality. Proceedings Sardinia 2005. Tenth International Waste Management and Landfill Symposium.

Ishii K., 2020. Hokkaido University, Japan. In: Cossu, R., Grossule, V. Lavagnolo, M.C., 2020. La discarica sostenibile: Ruolo nell'Economia Circolare e proposte normative. CISA publisher, ISBN: 97888 62650182.

Komilis D., 2020. Democritus University of Thrace, Greece. In: Cossu, R., Grossule, V., Lavagnolo, M.C., 2020. La discarica sostenibile: Ruolo nell'Economia Circolare e proposte normative. CISA publisher, ISBN: 9788862650182.

Kumpiene J., 2020. Luleå University, Sweden. In: Cossu, R., Grossule, V., Lavagnolo, M.C., 2020. La discarica sostenibile: Ruolo nell'Economia Circolare e proposte normative. CISA publisher, ISBN: 97888 62650182.

Ritzkowski, M., 2020. Hamburg University of technology, Germany. In Cossu, R., Grossule, V., Lavagnolo, M.C., 2020. La discarica sostenibile: Ruolo nell'Economia Circolare e proposte normative. CISA publisher, ISBN: 9788862650182
Sanchez A., 2020. Universitat Autònoma de Barcelona, Spain. In: Cossu, R., Grossule, V., Lavagnolo, M.C., 2020. La discarica sostenibile: Ruolo nell'Economia Circolare e proposte normative. CISA publisher, ISBN: 9788862650182.

Scharff, H., 2014. Sustainability and the EU landfill directive. In: Cossu R., van der Sloot H., 2014. Sustainable landfilling. Cap. 3, 75-83. CISA Publisher, ISBN: 978-88-6265-005-2.

Stegmann R., Heyer K.U., Hupe K., Ritzkowski M. (2003). Discussion of criteria for the completion of landfill aftercare. Proceedings Sardinia 2003. Ninth International Waste Management and Landfill Symposium.

Stegmann, R., Heyer, K.-U., Hupe, K. (2011): Do we have to take care of landfills forever? In: SARDINIA, 2011, Proceedings, 13. International Waste Management and Landfill Symposium, CISA, Contact: EuroWaste Srl, Padova, Italy.

Stegmann, R., Heyer, K.-U., Hupe, K., Willand, A. (2006): Deponienachsorge : Handlungs-optionen, Dauer, Kosten und quantitative Kriterien für die Entlassung aus der Nachsorge, Umweltforschungsplan des Bundesministeriums für Umwelt, Naturschutz und Reaktorsicherheit. Abfallwirtschaft, Förderkennzeichen (UFOPLAN) 204 34 327, im Auftrag des Umweltbundesamtes, 2006. see: http:// www.umweltdaten.de/publikationen/fpdf-l/3128.pdf or: http:// www.ifas-hamburg.de/pdf/UFOPLAN_IFAS.pdf

Stegmann, R., Heyer, K-U., Hupe, K., Ritzkowski, M., 2003, Discussion of criteria for the completion of landfill aftercare, Sardinia 2003 Proceedings of the 9. International Landfill Symposium, CISA - Environmental Sanitary Engineering Centre, Cagliari, Italy.

Thorneloe S., 2020. US.EPA, United States. In: Cossu, R., Grossule, V. Lavagnolo, M.C., 2020. La discarica sostenibile: Ruolo nell'Economia Circolare e proposte normative. CISA publisher, ISBN: 97888 62650182

van der Sloot H., 2020. van der Sloot Consultancy, Netherlands. In: Cossu, R., Grossule, V., Lavagnolo, M.C., 2020. La discarica sostenibile: Ruolo nell'Economia Circolare e proposte normative. CISA publisher, ISBN: 9788862650182.

van der Sloot, H., Hjelmar, O., Kosson, D.S., 2014. Test methods for waste leachability. In: Cossu R., van der Sloot H., 2014. Sustainable landfilling. Cap. 13, 621-631. CISA Publisher, ISBN: 978-886265-005-2.

van der Sloot, H., Kosson, D., van Zomeren, A., 2018. Landfilling of different kinds of waste: Leaching behavior. In: Cossu, R., Stegmann, R., 2018. Solid waste landfilling: Concepts, processes, technologies. Chapter 20.1, 1077-1094. Elsevier Publisher, ISBN: 9780128183366

WECD (1987). Our common future. Report of the World Commission on Environment and Development. Oxford University Press. 